\title{
Low Consumption Based on Family Needs
}

\author{
Hong-Hai HU \\ School of Economics, CUEB, Beijing, 100070, China \\ huhonghaimail@126.com
}

Keywords: Families need, Survivability consumption, Hedonic consumption, Development needs, Consumption function.

\begin{abstract}
In the whole family lifecycle consumption and saving of desire change is not only affected by external environment, by family survival needs more, hedonistic needs and development needs of its own factors such as family. Family survivability consumption has certain inertia and rigidity, family after meet the survivability of consumer demand, in the enjoyment and development between measures and determine the proportion of consumer spending and saving. In considering the family survival needs, hedonistic needs and development needs, we build a family with these need consumption function model, and carries on the empirical analysis; The study found that low survivability requirements and development cost is high in China's urban household consumption on the low side of the main reasons for a long time.
\end{abstract}

\section{Introduction}

Behind the economic slowdown in China's economic structure or changing. Generally believed that the original Chinese economic growth mainly based on investment and industry as the leading type of external demand, which is now rely more on external demand economic structure began to change, the consumer contribution to the economy from 2012 began to go beyond the investment, although It declined in 2012, but since 2014, the contribution of investment trends in the economy beyond the consumer more and more determined. China is the new economic growth mode transformation, from "producer Mode" to "consumer model." China's current focus is turned to rebalance the new model from the original model, and the completion of this conversion is the core of how to increase consumer spending residents.

On the relationship between consumption and production, Marx's "political economy Judgment" in the introduction has done insightful analysis, he pointed out: "Direct production is consumption; consumption is production of direct production target to produce consumption; consumption of Power is also the quality of consumption and production of the producer, because he needs some cause to pursue the purpose of the producer body." From these statements, we can find out the quality of consumption and production workers, ultimately promoting economic and social development and progress of power. Consumption of economic growth momentum is not an arbitrary decision, it is the inevitable product of history, is developed to a certain stage of the production decision, showing a prescriptive history.

Figure 1: Final consumption expenditure to GDP Growth Rate

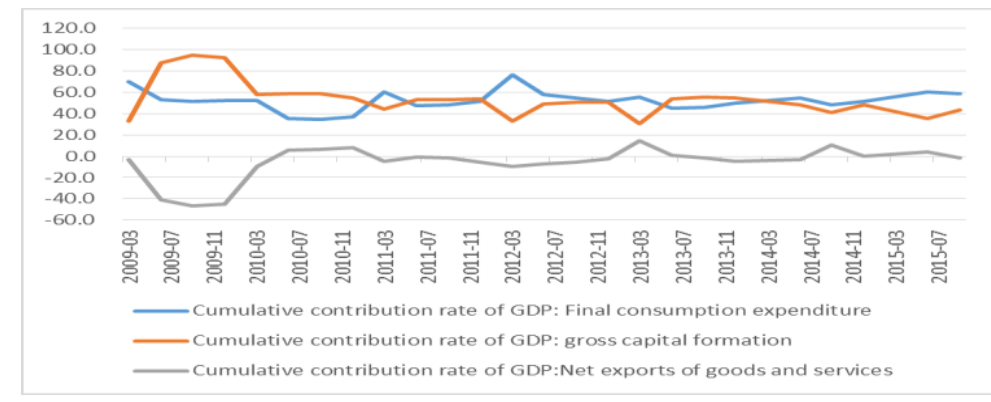

Source: wind 
Figure 2: Household final consumption expenditure proportion Sino-US comparison

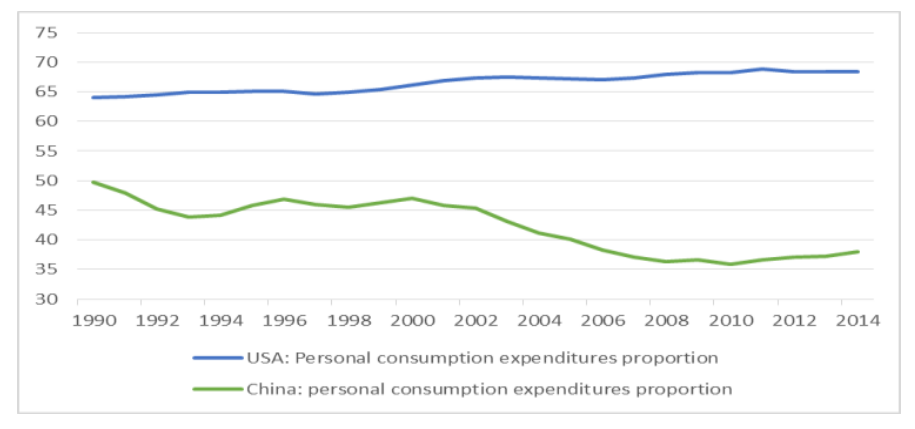

Source: wind

The key to rebalancing of our economy is consumption, especially household consumption can become support future economic growth in China a major force, improve household consumption is the key to achieving success from "Chinese exports" and "Chinese investment" to "Chinese consumption" Transition. Entered since 1990, with the rapid economic and social change and demographic scale of China's final consumption expenditure also showing a rapid increase. But consumer spending proportion point of view, preached a downward trend, although in recent years has increased, but the gap with the mature economies has not decreased consumption of less than residents still grim, insufficient consumption caused by insufficient domestic demand, making it difficult to achieve economic restructuring and rebalancing. At the same time, reduce the consumption of thousands of families also means that China cannot fully enjoy the fruits of the full economic and social development, and to some extent also reduced the welfare of the family.

The existing literature on the reasons for low consumption extensive research, the many interpretations to the life cycle theory as a basis, they found that China's low national consumption rate can be decomposed into two parts may be partially explained by the high growth explained partly by the change can be explained by demographic factors (kraay, 2000; Modliani Cao, 2004; Song and Yang, 2010; Dong Lixia and Zhao Wenzhe, 2011; Liu Shenglong, 2012). For demographic factors, Wang Wei (2010), Curtis et al. (2011) further research to move forward, that the increase in population and reduce labor consumption rate is the result of the implementation of China's family planning policy. But this interpretation and observation Zhoushao Jie (2009) is inconsistent, high savings rate in China Zhoushao Jie study in elderly households in the working population. The Chinese household consumption due to the low economic growth and changes in population patterns. The use of slow demographic changes are difficult to explain the rapid decline in China strong household consumption rate.

More research on the factors affecting China's household consumption for a more detailed analysis, also made a wealth of research findings. However, these studies did not grasp the profound Chinese household consumption characteristics, and thus concluded that relatively speaking there are certain limitations.

In this paper, an in-depth study of family survival needs, hedonic needs and basic development needs on that: after the family when survival needs basic household consumption, meet consumer family survival needs has rigidity family the current disposable income only first meet the basic consumption, in order to determining a proportion of consumption and savings; consumption and saving by families and family enjoyment desire development decisions, and family fun family desires and desires will be affected by the development of family life cycle costs and development of the family size, paper-based Construction empirical analysis of rigid consumer demand for household consumption function, the attempt to explain the Chinese household consumption prolonged slump reasons. 


\section{General Household Consumption Behavior Characterization}

To create a line with China's national conditions of the consumption function, we must first look at the characteristics of Chinese consumer behavior. The family is a social cell, and an economic cell. Family income has a production function, consumption function, reproductive function of education and social development functions. Currently, the family is the basic unit of personal consumption, which means that personal consumption spending data mainly carried out in the family, consumption is an important aspect of family economic behavior. Household consumption usually include consumption of material, consumer culture and education, health care consumption, leisure consumption and domestic service consumption. Household consumption behavior goal is to get the greatest satisfaction in consumer culture and the spirit of service for more than substance, seeking to maximize the utility of the family. In short, the goal is to ensure that household behavior to maximize the family well, to achieve this goal is ultimately to be embodied by household consumption. Consumption is important for the family economic behavior.

Engels household consumption needs into survival needs, enjoyment and development needs require three levels, and there is a progressive relationship between the three, made clear that with the advance of development of productive forces and relations of production, household consumption behavior from "survival need to "up to" pleasure needs Engels's description reveals the relative importance of the objective facts and the law: household consumption needs according to household purposes and development, divided into different levels, at the same time, household consumption is rising hierarchy of needs, there is a certain progressive relationship between the various levels. From a practical point of view of social development was observed, although the specific content of the current era of social and economic activities with Engels proposed levels of consumption theory has been a huge difference, but Engels consumption needs three levels of theory, research is still on our current consumption of family behavior has important theoretical significance.

We first examine the analysis of household consumption needs of survival consumption for survival, it is the family consumption in order to maintain the continuation of family life and reproduction of human life need, particularly in the form of human physiological needs to reflect, including greater consumption survival of family life aspects, mainly household consumption of food, clothing and other consumer content consumption and housing. Household consumption is the survival of the family to meet the basic physiological consumer spending. Family Survival consumption can be divided into simple survival survive consumption and expand consumption. The former refers to existing members of the family life reproduction of consumption or compensation; the latter is used to meet household consumption needs new family life, production and reproduction improve the quality of life needs. Family Survival content consumption accompanied by a rise in household income increases, relative and historical.

Family hedonic consumption is to further enhance the survival of the family on the basis of consumption. Follow Engels' view, when the development of productive forces of a society to a certain level, "survival needs" to enhance the "pleasure needs." And household consumption emphasis on survivability meet the physical needs of different family, more family hedonic consumption is used to meet the family psychological and spiritual needs. Marx believed that the biggest difference between humans and animals is that people have to meet the physical life than the pursuit, the pursuit of spiritual life more satisfying, more willing to pursue a conscious life activity. For families, household consumption is to achieve the maximization of family happiness, that is, through the family conscious consumer behavior, not only to achieve household substances meet, but also to make the whole family and to achieve the greatest satisfaction in the spiritual, cultural aspects. Household consumption behavior to achieve is to fully meet the family, therefore, household consumption is the family to meet the survival consumption basis, family members consciously in accordance with social and family beauty awareness, and actively pursue the consumer to meet their needs.

In the 21st century, global economic and social life into the information age. Production and human society lifestyle human society has undergone tremendous changes, these changes also to the 
development of the family brought new content. In the industrial age, industrial society demands of workers are skilled assembly line technique, in the information age, social labor requirements will reflect the content of knowledge and mental, for the quality of workers requires a more integrated and comprehensive, innovative become an essential quality of workers. In this context, the development needs of the family and will rise with the increase. Family Family Development is in response to the changing needs of the social environment to maximize intertemporal happy family, it is necessary to enhance the overall quality of family members to invest, the family can get better development in social development. Family Development as the implementation in the form of happy family intertemporal maximization, often lifting and accumulated household wealth is reflected in the quality of family life.

Development needs of the family to some extent, restricts household consumption desires. A general sense, the family needs to develop, and carry out more development investment period, household consumption desire for pleasure more easily suppressed, and this corresponds to the desire of families to accumulate wealth on the performance of the more intense; the development needs of a relatively small investment Family period, household consumption desire performance more strongly this time, household consumption society vulnerable to the impact of consumer fashion, Jealousy realized more obvious at this stage. Inverse relationship between the cost and the desire to consume both development of the family.

\section{Based on Family Survival Needs, Enjoyment and Development Needs Need Household Consumption Function}

Numerous studies support the continuity of household consumption characteristics (Smith, 2002; Wendner, 2003; Alessie and Lusardi, 1997; Fuhrer, 2000; Carroll, 2000). Based on this understanding, we believe that household consumption has the following characteristics; habitual, growth and the future of. For habitual consumption, we believe the time is divided as consumer preferences, that is, the current consumption level of effectiveness depends not only on the current situation of consumer spending, but also affected on a level of consumption. Growth, we believe consumers will have the same level of consumption of long tired of the reaction, the growth in consumption, but can bring physical and mental pleasure to consumers, increase consumer satisfaction, therefore, for the family in terms of consumer behavior, family They tend to have pursuit of profit or increase consumption of consumer preferences. In terms of the future, we believe that household consumption while also considering the future growth of changes in household consumption. On this basis, we believe that household consumption first meet consumption habits, to maintain quality of life for families and at least the same level of pre-followed by consumption and savings decisions on this basis. Thus, we can derive the optimal household consumption function.

First, since the presence of basic survival needs and habits of the family of each period budget constraint is:

$$
w_{t+1}=R\left(w_{t}+y_{t}-c_{t-1}-\Delta c_{t}\right)
$$

In the right side of equation $R$ interest rate, $c_{t-1}$ is to ensure that consumers in the period thedonic consumption of both consumer level, $\Delta c_{t}$ the current implementation.

$w_{t}+y_{t}-c_{t-1}-\Delta c_{t}$ is the accumulation of Family Development.

Then we give household consumption period t utility function of the form: $u\left(c_{t-1}, \Delta c_{t}\right)$.

Our previous analysis that the development needs of the family also affect the current expenditure of the family, we have the desire to develop family-related variables denoted by $D_{t}$, the optimal decision household consumption can be written as follows:

$$
\begin{array}{r}
E \sum_{t=0}^{N} \beta^{t} u\left(c_{t-1}, \alpha c_{t}\right) v\left(D_{t}\right)+v_{N+1}\left(w_{N+1}\right) \\
\text { s.t. } \quad w_{t+1}=R\left(w_{t}+y_{t}-c_{t-1}-\Delta c_{t}\right)
\end{array}
$$

The constraints can be expanded: 


$$
\begin{aligned}
& \Delta c_{t}=\left[\left(w_{t}+y_{t}-c_{t-1}\right)-w_{t+1}\right] / R, c_{t+1}=c_{t}+\Delta c_{t}\left(1^{\prime}\right) \\
\Delta c_{t+1}= & {\left[R\left(w_{t+1}+y_{t+1}-c_{t}\right)-w_{t+2}\right] / R, c_{t+1}=c_{t}+\Delta c_{t+1}\left(1^{\prime \prime}\right) }
\end{aligned}
$$

$c_{t}$ is observed in the above constraints in the current household consumption, while D is separable. The objective function with $w_{t+1}$ respect to a derivation, we get a first-order conditions are as follows:

$$
\begin{aligned}
& u^{\prime}(t)=\beta E\left[R u^{\prime}(t+1) v\left(D_{t+1}\right)\right] / v\left(D_{t}\right)^{+}{ }^{\left[u^{\prime}(t+1)-u_{1}(t+1)\right] v\left(D_{t+1}\right)} / v\left(D_{t}\right)^{+} \beta\left[u^{\prime}(t+2)-u_{1}(t+2)\right] v\left(D_{t+2}\right) / v\left(D_{t}\right)^{(-1)^{\prime} R}+\ldots \\
& +\beta^{N-t-1}\left[u^{\prime}(N)-u_{1}(N)\right] v\left(D_{N}\right) / v\left(D_{t}\right)^{(-1)^{(N-N-1)} R}
\end{aligned}
$$

Household consumption satisfies the first period $\mathrm{N}$ :

$$
v\left(D_{N}\right) u^{\prime}(N)=R \beta v_{N+1}^{\prime}\left(w_{N+1}\right)
$$

Solutions to the above explanation:

The first is the impact of consumption on the optimal survivability consumer behavior. Because of habitual, household consumption for the next issue of the survival of consumption, lower consumption of pleasure in the future to meet the survival consumption will be negatively affected by the current consumption of the survival of consumer spending. That is, with increasing the survivability of consumption lead to reduced consumption of pleasure, under the next phase of hedonic consumption will increase. Showing a zigzag.

Secondly, the relationship between the family and the desire to develop between the desire for pleasure. Family Development will increase the desire to suppress the desire for happiness of the family, the desire to increase household wealth accumulation, that is, the desire to increase the development of the family household consumption will reduce the marginal utility. This is because the variable is assumed that the utility function is separable in the development of desire, that is, V (D) with the desire to reduce development cost increases.

Here we consider the Euler equations, and (3) do second order Taylor expansion to give consideration family conditions for development of precautionary savings expressions:

$$
\begin{aligned}
& E\left[\left(\Delta c_{t+1}-\Delta c_{t}\right) / \Delta c_{t}\right]=E\left[\left(v\left(D_{t}\right) / R \beta v\left(D_{t+1}\right)-1\right]\left(u^{\prime} / u^{\prime} \Delta c_{t}\right)\right. \\
& +\frac{1}{2}\left(-u^{\prime \prime} / u^{\prime} \Delta c_{t}\right) E\left[\left(\Delta c_{t+1}-\Delta c_{t}\right)^{2}\right]
\end{aligned}
$$

On the right-hand side of the first term is not considered precautionary saving Euler equation that represents hedonic consumption expenditure of households with family development need to reduce costs increases, the second term is precautionary savings, at the same time the family pleasures CCE also with the precautionary saving changes in demand.

According to the equation, we can see that each issue will have an impact on consumer consumption next issue, that consumption is a function of each issue of the consumption of the equation (3) solving available:

$$
\left\{c_{t}: c_{t}=F\left(c_{0}, \ldots, c_{t-1}, y_{t}, w_{t}, D_{t}, R, \beta\right)\right\}_{t=0}^{N}
$$

\section{Empirical Analysis}

\section{Data Description}

Follow Gourinchas and Parker (2002) method, when the family utility function is constant relative risk aversion, it is also detachable, when the equation (5) represented by the solution represented by the following formation:

$$
\log C_{t}=\alpha_{0}+\alpha_{1} \log Y_{t}+\alpha_{2} \log W_{t}+\alpha_{3} \log D_{t}+\alpha_{4} \log C_{t-1}+\cdots+\alpha_{5} \log C_{0}+\varepsilon_{t}
$$


Which for the first $t$ of observed household consumption expenditure, the argument to the right of the equation are income, household wealth accumulation, as well as the cost of the development needs of the family before each period of consumer spending.

To verify the equation (7), as used herein, "China Statistical Yearbook" and WIND data from 1997 to 2014 the average household consumption expenditure in 31 provinces urban and rural areas, income, and educational expenditure statistics panel data empirical test. Use the cumulative net income represented families accumulate wealth. Use family population structure to reflect the family life cycle, education spending as a family development costs of alternative variables.

\section{Select Econometric Model}

According to the above analysis and formula (2) and the equation (7), you can have the following regression model:

$$
\begin{array}{r}
\log C_{i t}=\alpha+\alpha_{1} \log Y_{i t}+\alpha_{2} \log W_{i t}+\alpha_{3} \log \text { Feed }_{i t}+\alpha_{4} \log F e e d O_{i t}+\alpha_{5} \log E_{i t}+\alpha_{6} \log C_{i t-1} \\
+\cdots+\alpha_{n} \log C_{i t-s}+\varepsilon_{i t}
\end{array}
$$

Wherein, $\log C_{i t}$ for the value of household consumption, $\log Y_{i t}$ is the logarithm of family income, $\log W_{i t}$ cumulative net income for the family, $\log F e e d C_{i t}$ is 0 -14-year-olds accounted for the proportion of the population aged 15-64 logarithm, $\log$ Feed $_{i t}$ is 65 years and the proportion of the population over the population aged 15-64, $\log C_{i t-1}$ is family investment spending on education as an alternative to the amount of the cost of development of the family. $\log E_{i t}$ And $\log C_{i t-s}$ is upfront consumer spending. ${ }^{\varepsilon_{i t}}$ Is a random disturbance term.

\section{Estimation Methods and Results}

\section{Estimation Methods}

We use dynamic panel GMM estimation method on empirical methods. Reasons for adopting this approach is that the method has the following advantages, firstly, because of consumption affected the survival of consumption, and the face of fluctuations in income, consumers may smooth their consumption, household consumption data may be compared with other years have more viscous, and dynamic panel model can identify this sticky; the second is between household consumption and a number of explanatory variables is likely to be decided at the same time, this causes problems endogenous explanatory variables, dynamic panel GMM estimation can effectively control a large extent endogenous problem; third GMM estimated using differential conversion data, you can avoid the problem of unobservable variables and explanatory variables relating to, or omitted variable problem.

According to the existing literature normal processing methods, we children and the elderly dependency ratio as exogenous variables. The other variables in our model as either weak exogenous, or as a pre-set, we use "internal tool" that is weakly exogenous or predetermined variables lagged values as their own instrumental variables are listed in Table 2 a dynamic panel GMM estimation of the level of difference equations and equations used tools and lag order, and gives the test residuals autocorrelation AR (1), AR (2) statistics and corresponding p-value test tool joint Sagan statistic validity of the corresponding p-value. AR on residual autocorrelation test (1) and AR (2) are 0.009 and 0.380 respectively, so we have no model residuals autocorrelation hypothesis cannot be rejected; while the p-value for the tool joint valid hypothesis Sagan statistics is 0.937, cannot reject the null hypothesis effective tool joint, so we selected instrumental variables is appropriate.

\section{Regression Analysis}

Table 2 shows the results of the regression of basic theoretical model constructed in this paper is to analyze the following issues: household consumption and survival hedonic consumption is different 
desires, they have a different role in meeting family needs; survival needs by history consume content decisions. According to the theoretical model established in this analysis, so that the necessary conditions for the establishment of the above is the impact on future consumption is decreasing, which is also an expanded interpretation of the Euler equations. The empirical results show a lag of two coefficients also showed a decreasing characteristic.

Table 1: GMM dynamic panel estimates household consumption

\begin{tabular}{|c|c|}
\hline The dependent variable $: \log C_{i t}$ & ONE -STEP SYS-GMM \\
\hline Explanatory variables & Regression coefficients \\
\hline CONSTANT & $0.412 * *(7.76)$ \\
\hline $\log Y_{i t}$ & $0.841 * *(53.62)$ \\
\hline $\log W_{i t}$ & $-0.001 * *(-4.97)$ \\
\hline $\log$ Feed $_{i t}$ & $-0.079 * *(-3.21)$ \\
\hline $\log \mathrm{FeedO}_{i t}$ & $0.266 * *(3.54)$ \\
\hline $\log E_{i t}$ & $-0.0351 *(-2.05)$ \\
\hline$\overline{\log C_{i t-1}}$ & $0.007 * *(3.46)$ \\
\hline $\log C_{i t-2}$ & $-0.001 * *(-1.94)$ \\
\hline
\end{tabular}

Note: ${ }^{*}, *$,Respectively, at the $5 \%$ and $1 \%$ significance level significantly.

Above theoretical model also noted that the development will affect the family desires each period hedonic consumption, namely, the development needs of the family household consumption will have an impact. In the empirical test showed that the population burden burden ratio parameter children, education expenditures represent different aspects of the development of the family, also shows a significant parameter family desire to develop a significant negative impact on household consumption desires. Survival consumption household consumption may well explain the function of spontaneous consumption characteristics. Current income is still an important factor in enhancing consumption.

\section{Conclusions and Policy Implications}

Based on the reference Engels divided on consumption and previous analysis of the literature and research on this basis, we proposed the establishment of a Chinese urban family life cycle for household consumption function and the use of national urban household consumption related to check the validity of the model. For this article first Chinese household consumption behavior analysis reveals the characteristics of household consumption, consumption by expanding the standard model, the establishment of a broader contain Euler equation, indicating consumption due to family survival is not only historical and relative Effect of the current consumer spending, will also affect the future of household consumption expenditure, but this effect is diminishing, showing a jagged features. Family Survival consumption may well explain the Keynesian consumption theory of spontaneous consumption fluctuations, hedonic consumption and the development needs of the family can explain marginal propensity to consume change.

Our quantitative analysis using 1997-2014 panel data of Chinese provinces throughout the city, discovered and confirmed the theoretical analysis. Since household consumption demand is determined by the spontaneous consumer demand and the marginal propensity to consume, spontaneous consumption can be explained by the existence of consumer demand, the marginal propensity to consume may be determined by hedonic consumer demand and domestic development needs to explain. Therefore, the low cost of development of Chinese families to increase survivability 
and household consumer demand leading to lower household consumption expenditure mainly due to China.

According to the above empirical analysis, we propose the following policy recommendations: First, to speed up the social security system, to build family support system development, accelerate the improvement of health care system in order to broaden the content of Chinese household consumption to survive, direct expansion of Chinese households survivability consumer spending. Second, speed up restructuring and supply-side reforms to improve the content of domestic demand needed to expand the scope and content of the household hedonic consumption, and further enhance the effectiveness of hedonic consumption brings. Promote long-term savings to the family as soon as possible an effective transformation of the actual purchase. Supply-side reform must meet the higher levels of consumer demand to start, speed up the adjustment and upgrading of the consumption structure of supply, increase the supply of goods and durable fashion and personalized products, in particular to increase the supply of goods and services, promote the expansion of household consumption expenditure. Third, increase public goods and services, in particular by increasing the development of family support, the introduction of more family welfare policies and measures to reduce the expected cost of the family's future development, China is conducive to resolving family residents to reduce current consumption, excessive savings problems, but more importantly, it is also conducive to the health of our economy and society and sustainable development.

\section{References}

[1] Angrist, Josh, 2002, "How Do Sex Ratios Affect Marriage and Labor Markets? Evidence from America's Second Generation," Quarterly Journal of Economics, 997-1038, August.

[2]Aziz, Jahangir, and Li Cui, 2007, "Explaining China's Low Consumption: The Neglected Role of Household Income,” IMF working paper 07/181.

[3]Bayoumi, Tam, Hui Tong, and Shang-Jin Wei, 2009, "The Chinese Corporate Savings Puzzle: A Little International Comparison Can Go a Long Way," Unpublished working paper, IMF and Columbia University.

[4]Beck, Thomas and Ed Al-Hussainy, Financial Structure Dataset, The World Bank/DECRG-FI, Washington. August 2007.

[5]Blanchard, Olivier J. and Francesco Giavazzi, 2005, "Rebalancing Growth in China: A Three-Handed Approach.” MIT Department of Economics Working Paper No. 05-32.

[6]Brown, Philip H., Erwin Bulte, and Xiaobo Zhang. 2010. "Positional Spending and Status Seeking in Rural China," Journal of Development Economics, forthcoming. American Mathematical Monthly, 69: 9-14.

[7]Campbell,J.,and J.Cocco,2007,"How Do House Prices Affect Consumption? Evidence from Micro Data”,Journal of Monetary Economics.Vo1.54.591-621.

[8]Carroll, C.D., 1997, "Buffer-Stock Saving and The Life cyc1e/ Permanent Income Hypothesis", Quarterly Journal of Economics, Vo1.112, 1-55.

[9]Carroll,C.D.,M.Otsuka,and J.Slacalek,2011,"How Large Is The Housing Wealth Effect: A New Approach",Journal of Money,Credit,and Banking,Vo1.43,55- 79.

[10]Chamon,M.,and E.Prasad,2010,"Why Are Saving Rates of Urban Households in China Rising?”,American Economic Journal-Macroeconomics.Vo1.2.93-130.

[11]Deaton, A., 1992, Understanding Consumption,Oxford University Press,USA.

[12]Ge,S.; Yang,D.T. and Zhang,J. "Population Policies,Demographic Structural Changes,and the Chinese Household Saving Puzzle.” IZA Discussion Paper No.7026, 2011. 